\title{
Biodiesel: o ônus e o bônus de produzir combustível
}

\author{
Biodiesel: the charge and the bond of the fuel producing
}

Paulo Regis Ferreira da Silva ${ }^{\mathrm{I}^{*}}$ Thais Fernanda Stella de Freitas $^{\mathrm{I}}$

\section{- REVISÃO BIBLIOGRÁFICA -}

\section{RESUMO}

A dependência do petróleo e a poluição gerada pelo óleo diesel são as grandes desvantagens do uso deste combustível, o que vem estimulando a busca por fontes energéticas alternativas. Biodiesel é o combustível derivado de óleos vegetais ou de gordura animal que pode substituir total ou parcialmente o óleo diesel derivado de petróleo. Pode ser obtido por diferentes processos, como craqueamento, transesterificação ou esterificação, tendo glicerina como subproduto. A transesterificação é o método estimulado pelo Programa Nacional de Produção e Uso de Biodiesel no Brasil, consistindo na reação química de triglicerídios com álcoois (metanol ou etanol) na presença de um catalisador $(\mathrm{NaOH})$. O objetivo desta revisão é discutir as vantagens e as desvantagens que a produção de biodiesel traz para a agricultura e o ambiente e a competição que pode ocorrer por recursos naturais entre a produção de alimentos e a de combustível. O biodiesel, além de ser obtido de fontes renováveis, tem como vantagens a menor emissão de gases poluentes e a menor persistência no solo. Entretanto, o custo de produção atualmente é maior e o balanço energético, apesar de variar com o sistema de produção utilizado, é menos favorável em relação ao óleo diesel. A maior demanda por grãos oleaginosos promoverá a utilização de mais espécies nos sistemas de produção em todo o país. Na Região Sul, tem sido dado maior enfoque às culturas da soja, girassol, canola e mamona. Esta última, incentivada em regiões de baixa disponibilidade hídrica, está sendo melhorada geneticamente para produção de biocombustível. Tem como desvantagem a presença de ricina, substância tóxica ao homem e que pode contaminar o ambiente. $O$ girassol e a canola produzem óleos "nobres" para alimentação humana, com altos teores de ácidos graxos poliinsaturados. O biodiesel constitui-se em uma boa alternativa para a substituição parcial ou total do óleo diesel, mas as vantagens ambientais e agrícolas dependem de estudos pendentes em vários elos da cadeia produtiva.

Palavras-chave: biocombustível, energia renovável, culturas oleaginosas, custo energético.

\begin{abstract}
The petroleum dependence and the pollution generated by its use are the big disadvantages of this fuel, which demand look for another source of energy. Biodiesel is the fuel obtained from vegetables oils or animal fat, which can substitute petroleum diesel, total or partially. Three processes are possible to obtain biodiesel: cracking, tranesterfication or esterification, having glycerin as a derivate. The Brazilian National Program for Production and Use of Biodiesel stimulates the transesterification process, which is the chemical reaction of the triglycerides with alcohols (methanol or ethanol) using a catalyst (NaOH). The goal of this revision was to discuss the advantages and disadvantages that biodiesel production can bring for agriculture and environmental and the competition that could occur for natural resources between food and fuel production. The biodiesel obtained from renewable sources has as advantages the lower pollutant it gases emission and lower persistence in the soil. However, it has a higher cost production than petroleum diesel and the energy balance is less favourable, although it can vary with the system production used. The higher demand for oleaginous grains will increase the number of species used in crop production. In the south of Brazil, the species more stimulated are soybean, sunflower, canola and castor plant. Castor, that is an alternative for drought regions, is being genetically modified for fuel production, but it has the big disadvantage of ricin production, which is very poisonous for human and environment. Sunflower produces a very healthy oil for human use, with high levels of fat poliinsaturated acids. Biodiesel is a good alternative to substitute partial or totally petroleum diesel, but the environmental and agricultural advantages depend on studies in every link of its production chain.
\end{abstract}

Key words: biofuel, renewable energy, oil crops, energy cost.

\section{INTRODUÇÃO}

Em 1900, o inventor alemão Rudolph Diesel levou à exposição internacional de Paris um motor com

IPrograma de Pós-graduação em Fitotecnia, Faculdade de Agronomia, Departamento de Plantas de Lavoura, Universidade Federal do Rio Grande do Sul (UFRGS), Porto Alegre, RS, Brasil. E-mail: paulo.silva@ufrgs.br. *Autor para correspondência. 
novo sistema de funcionamento, chamado de "ciclo Diesel”. O motor era movido com óleo de amendoim e, nas primeiras décadas do século XX, foram utilizados óleos de várias outras espécies vegetais para seu funcionamento. $\mathrm{O}$ alto custo de produção de sementes desde aquela época foi uma dificuldade para utilização do motor Diesel. A abundância de petróleo no início do século XX e o baixo custo para refino de seu óleo fez com que os óleos vegetais fossem substituídos pelo óleo refinado de petróleo, que então foi chamado de “óleo diesel”. Nas décadas de 30 e 40, óleos vegetais eram utilizados apenas em caso de emergência (MA \& HANNA, 1999).

Além de sua grande disponibilidade no início do século, a alta densidade energética do petróleo colaborou para torná-lo a matéria-prima mais conveniente para combustíveis utilizados nos setores de transporte, agricultura e indústria. Segundo o Ministério da Ciência e Tecnologia do Brasil (2005), a matriz energética mundial tem participação de $80 \%$ de fontes de carbono fóssil, sendo 36\% de petróleo. No Brasil, a participação do petróleo é ainda maior, na ordem de 43\%. Entretanto, os combustíveis fósseis são grandes poluidores do ambiente, seja pela emissão de gases de efeito estufa durante a combustão, seja pelo descarte de resíduos ou pelos derramamentos que eventualmente ocorrem no mar e no solo. Além destes inconvenientes, não são raros os anos em que o consumo excede a produção (INTERNATIONAL ENERGY AGENCY, 2006). Este crescente consumo, a concentração geográfica das jazidas e a volatilidade do preço do petróleo vêm causando guerras entre países, o que já gerou a chamada “crise do petróleo”.

Diante dessa situação, na década de 70, o governo brasileiro lançou o programa Pró-Álcool como uma estratégia para reduzir o consumo de gasolina, lançando carros movidos a etanol. O programa fomentava a fabricação de veículos movidos exclusivamente a álcool, extraído da cana-de-açúcar. Foi um sucesso na década de 80 , quando $90 \%$ dos carros produzidos no Brasil eram movidos a álcool (BRASIL, 2005). A dependência exclusiva da cana-deaçúcar e a inexistência de mercado externo de etanol foram as principais limitações do programa, pois impediam que o governo regulasse o preço do combustível ao consumidor. A sazonalidade da produção e a competição do álcool com o açúcar no mercado externo causavam grandes oscilações de preço. Além disso, a tecnologia incipiente dos motores naquela época também causou rejeição pelos consumidores.

Como a maioria dos cenários traçados para o preço internacional do petróleo prevê a continuidade da escalada de preços e de consumo (BRASIL, 2005; GREENE et al., 2006), consolida-se a necessidade de algum combustível alternativo que reduza o consumo de petróleo. Os Estados Unidos têm investido em estudos sobre a produção de etanol a partir de sorgo, milho e eucalipto (PIMENTEL \& PATZEK, 2005). A outra “nova” alternativa é a utilização de óleos vegetais, como Rudolph Diesel fez no princípio de sua invenção. Esta necessidade tem levado muitos países, inclusive o Brasil, a investir em programas de produção de óleos vegetais para substituir-se o óleo diesel. Em 2005, o Ministério da Ciência e Tecnologia (MCT) lançou o Programa Nacional de Agroenergia e o Programa Nacional de Produção e Uso do Biodiesel, que prevêem a produção de combustíveis a partir de fontes renováveis, decretando também uma lei que determina a adição de biodiesel ao óleo diesel derivado do petróleo. Diante desse cenário, o objetivo desta revisão é o de avaliar as vantagens e as desvantagens que a produção de biodiesel pode trazer para a agricultura e para o ambiente e discutir a competição por recursos naturais que haverá entre a produção do combustível e de alimentos.

\section{Características do biodiesel}

Biodiesel é o combustível biodegradável derivado de fontes renováveis, como óleos vegetais “puros” ou já utilizados e gorduras animais. É obtido por diferentes processos, como craqueamento, esterificação ou transesterificação. Pode ser utilizado puro ou em misturas com óleo diesel derivado do petróleo, em diferentes proporções. Quando o combustível provém da mistura dos dois óleos, recebe o nome da percentagem de participação do biodiesel, sendo B2 quando possui 2\% de biodiesel, B20 quando possui 20\%, até chegar ao B100, que é o biodiesel puro.

O método de obtenção de biodiesel que o governo brasileiro incentiva é o de transesterificação (Figura 1), que consiste na reação química de triglicerídeos com álcoois (metanol ou etanol) na presença de um catalisador (ácido, básico ou enzimático), resultando na substituição do grupo éster do glicerol pelo grupo etanol ou metanol. A glicerina é um subproduto da reação, e deve ser purificada antes da venda para se aumentar a eficiência econômica do processo. A produção brasileira de biodiesel deve utilizar o etanol no processo, por ser produzido em abundância e com baixo custo (BRASIL, 2005).

O custo de produção do biodiesel continua sendo um grande obstáculo na sua produção. ZHANG et al. (2003) citam um custo de produção do biodiesel de aproximadamente US\$0,5 $^{-1}$, enquanto o óleo diesel derivado do petróleo apresenta um custo de US\$0,36 $\mathrm{l}^{-1}$. 


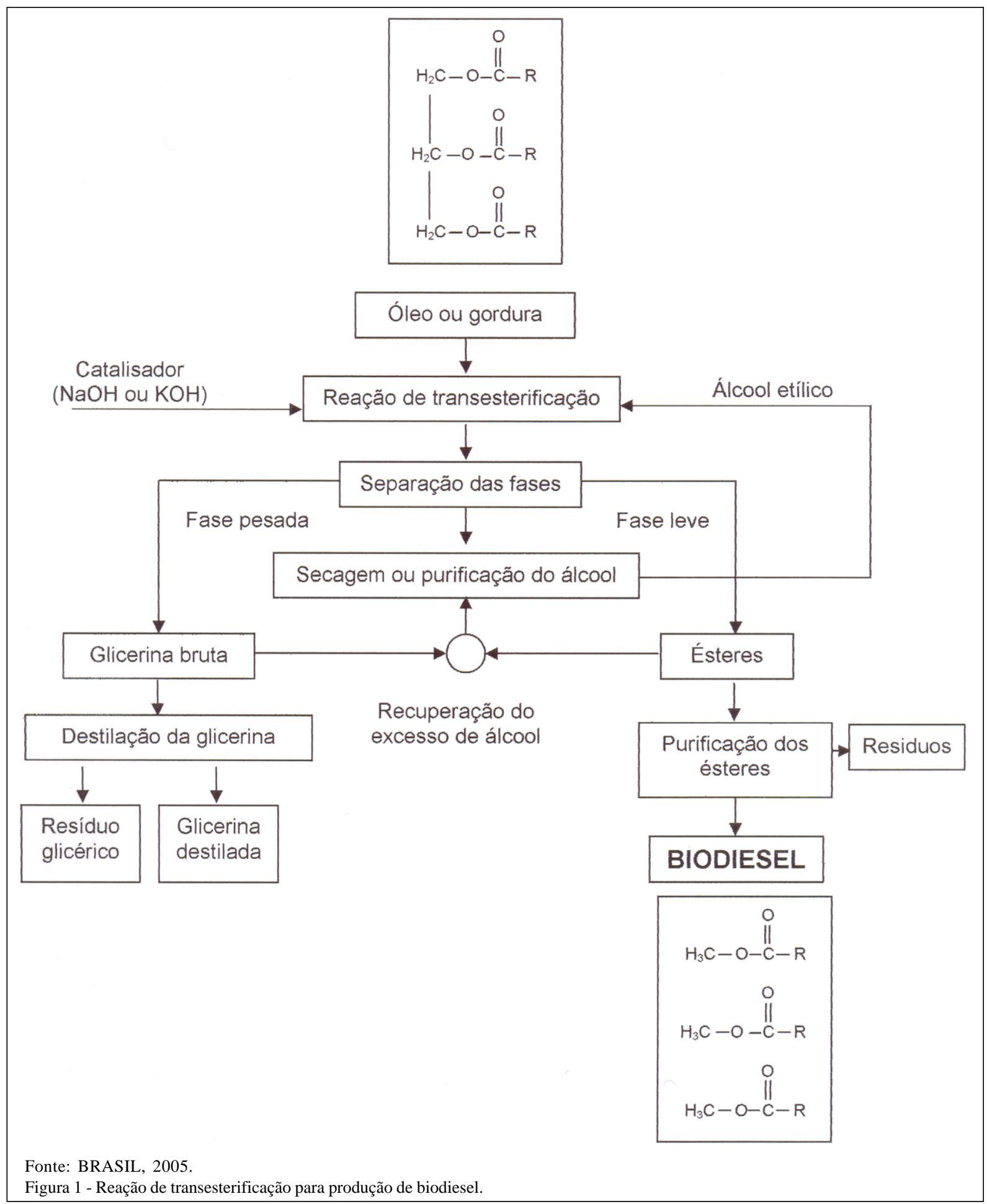

Em busca de alternativas viáveis, várias espécies vegetais estão sendo estudadas para extração de óleo, como a microalga Chlorella protothecoides que, quando se desenvolve heterotroficamente, apresenta alto conteúdo lipídico (55\%) nas células e elevada produção de biomassa em tempo menor que o das culturas oleaginosas tradicionais (MIAO \& WU, 2006). O custo de produção é muito variável, pois depende da matéria prima e do processo utilizado, além do local onde é produzido. A maior demanda pode estimular a produção de oleaginosas, aumentando a escala de produção e oferta grãos, o que pode resultar em 
diminuição do custo. No entanto, pode aumentar a competição entre a produção de alimentos e a produção de combustível, resultando em maior valor dos grãos e elevando o custo de produção. A reutilização de óleo de cozinha é outra alternativa de redução do custo de produção, além de contribuir para a solução do problema de descarte deste produto (ZHANG et al., 2003).

Consequências do uso de biodiesel para o ambiente

A menor emissão de gases poluentes é uma das principais vantagens do uso de biodiesel. BARNWAL \& SHARMA(2005) analisaram a emissão de gases poluentes pelas combustões de biodiesel e de óleo diesel de petróleo, obtendo resultados favoráveis para o biocombustível. Concluíram que o $\mathrm{SO}_{2}$ é totalmente eliminado, a fuligem diminui em $60 \%$, o monóxido de carbono e os hidrocarbonetos diminuem em 50\%, os hidrocarbonetos poliaromáticos são reduzidos em mais de $70 \%$ e os gases aromáticos diminuem em 15\% (Figura 2). Em estudo realizado, em 1998 pelos Departamentos de Agricultura (USDA) e de Energia (USDE) dos Estados Unidos sobre a emissão de gás carbônico $\left(\mathrm{CO}_{2}\right)$ pelo biodiesel produzido de soja, desde a produção agrícola até à queima pelo motor, e do diesel de petróleo, da extração à combustão, as emissões de $\mathrm{CO}_{2}$ pelo B20 e pelo B100 foram, respectivamente, $15,7 \%$ e $78,5 \%$ menores que as do óleo diesel derivado de petróleo. Entretanto, esse mesmo estudo concluiu que a emissão de alguns gases é maior durante a combustão do biodiesel, como a de óxidos de nitrogênio ( $\mathrm{NO}$ e $\mathrm{NO}_{2}$ ), cuja soma aumenta em 2,6\% na mistura B20 e em 13,3\% no B100, e a de ácido clorídrico (HCl), que aumenta em 2,8\% no B20 e em $13,6 \%$ no B100.

A toxicidade de um composto para o solo depende das características de cada tipo de solo, e de sua concentração e atividade sobre a biota. LAPINSKIENÈ et al. (2006) avaliaram a toxicidade do biodiesel e do óleo diesel no solo em concentrações de 1 a $13 \%$ de massa do solo. Em solo contaminado com biodiesel, as atividades respiratórias dos microrganismos e das enzimas desidrogenases cresceram quando a concentração aumentou até $13 \%$. Em solo contaminado com óleo diesel de petróleo, essas atividades aumentaram até a concentração de 3\% e diminuíram em concentrações maiores, ficando abaixo da atividade do solo não contaminado (controle), determinando toxicidade do óleo diesel quando em concentração maior que $3 \%$.

A eficiência energética do biodiesel foi estudada por PIMENTEL \& PATZEK (2005). Estes autores somaram a energia de todos os insumos utilizados na produção de grãos de soja e de girassol (Tabelas 1 e 2). Para a produção de $1500 \mathrm{~kg}$ de grãos de girassol, foram gastos 6,119Gcal, com a maior parcela estando contida no adubo nitrogenado (1,76Gcal). Sabendo que a cultivar utilizada contém $26 \%$ de óleo, são necessários $3920 \mathrm{~kg}$ de grãos, que fornecem 15,99Gcal, para a obtenção de 1000kg de óleo. Somados

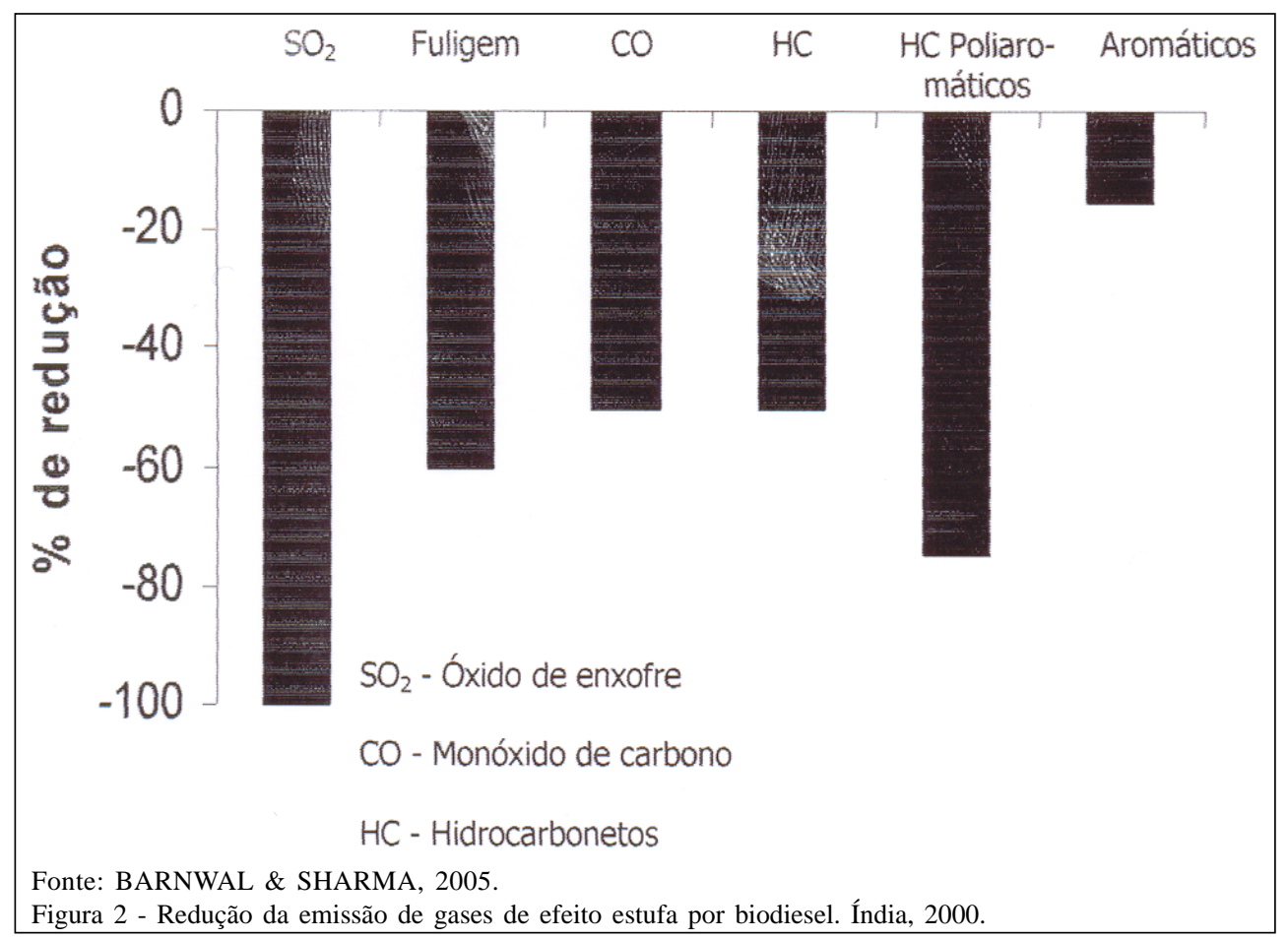

Ciência Rural, v.38, n.3, mai-jun, 2008. 
Tabela 1 - Gasto de energia para a produção de $1.000 \mathrm{~kg}$ de biodiesel de girassol.

\begin{tabular}{lll}
\hline \multicolumn{1}{c}{ Energia para a produção de 1.500 kg de grãos } & Quantidade & Gcal \\
\hline Mão de obra & $8,6 \mathrm{~h}$ & 0,344 \\
Maquinário & $20 \mathrm{~kg}$ & 0,36 \\
Diesel & $180 \mathrm{l}$ & 1,8 \\
Nitrogênio & $110 \mathrm{~kg}$ & 1,76 \\
Fósforo & $71 \mathrm{~kg}$ & 0,293 \\
Potássio & $100 \mathrm{~kg}$ & 0,324 \\
Calcário & $1000 \mathrm{~kg}$ & 0,281 \\
Semente & $70 \mathrm{~kg}$ & 0,56 \\
Herbicida & $3 \mathrm{~kg}$ & 0,3 \\
Eletricidade & $10 \mathrm{kWh}$ & 0,029 \\
Transporte & $270 \mathrm{~kg}$ & 0,068 \\
& & 6,119 \\
Subtotal & & \\
Energia para a produção de $1.000 \mathrm{~kg}$ de biodiesel & & 15,99 \\
Grãos & & 0,697 \\
Eletricidade & $3.920 \mathrm{~kg}$ & 1,35 \\
Vapor & $270 \mathrm{kWh}$ & 0,16 \\
Água & $1.3510^{6} \mathrm{kcal}$ & 0,592 \\
Calor & $0.1610^{6} \mathrm{kcal}$ & 0,3 \\
Perdas & $0.5910^{6} \mathrm{kcal}$ & 0,404 \\
Aço & $0.310^{6} \mathrm{kcal}$ & 0,106 \\
Cimento & $32 \mathrm{~kg}$ & 19,599 \\
Total & $56 \mathrm{~kg}$ & \\
\hline
\end{tabular}

Fonte: PIMENTEL \& PATZEK, 2005.

os processos de extração do óleo, são gastos 19,599Gcal para a extração de $1.000 \mathrm{~kg}$ de óleo de girassol. Como qualquer óleo, uma tonelada tem o conteúdo energético de 9Gcal. Assim, o processo de produção de biodiesel a partir de grãos de girassol tem uma perda de $54 \%$ de energia. Nesse mesmo estudo, o biodiesel produzido a partir de grãos de soja apresentou perda energética menor (21\%). Para a produção de $2.668 \mathrm{~kg}$ de grãos, foi necessário um gasto de 3,746Gcal, em que apenas 0,06Gcal são de adubo nitrogenado. Com um conteúdo de $18 \%$ de óleo nos grãos, são necessários $5.556 \mathrm{~kg}$ de grãos, que fornecem 7,8Gcal. Adicionada a energia necessária para a extração do óleo, são gastos 11,409Gcal para a obtenção de $1.000 \mathrm{~kg}$ de biodiesel, que fornecem $9 \mathrm{Gcal}$. A perda de energia neste processo é, portanto, de $21 \%$.

A eficiência energética do biodiesel depende de fatores como gasto energético na produção e o teor de óleo dos grãos utilizados. Vários autores (FREDERIKSSON et al., 2006; JANULIS, 2004; POWLSON et al., 2005) vêm estudando o balanço energético de biocombustíveis, como etanol e biodiesel, tendo encontrado resultados variáveis para processos que utilizam a mesma matéria-prima. Nos estudos realizados pelo USDA e pelo USDE (1998), houve uma perda de $19,45 \%$ para o biodiesel produzido de soja. O sistema agrícola adotado, com maior ou menor número de operações de preparo de solo, por exemplo, é fundamental para um balanço energético favorável. Além disso, o balanço energético depende dos fatores considerados pelos autores, que pode somar à energia do biocombustível a energia contida em subprodutos, como o farelo da soja, por exemplo, o que diminui as perdas do processo. A mão-de-obra é um fator muitas vezes desconsiderado no gasto energético.

\section{Culturas com potencial para utilização}

As práticas agrícolas adotadas no cultivo das espécies produtoras de biodiesel são aspectos determinantes das eficiências econômica e energética do processo de obtenção de biodiesel. Devido à diversidade climática e à grande extensão territorial, nove culturas são indicadas para a extração de biodiesel no país. A tabela 3 lista as espécies consideradas potenciais pelo Ministério da Ciência e Tecnologia e o potencial produtivo de cada uma. As espécies com 
Tabela 2 - Gasto de energia para a produção de 1.000kg de biodiesel de soja.

\begin{tabular}{|c|c|c|}
\hline Energia para a produção de $2.668 \mathrm{~kg}$ de grãos & Quantidade & Gcal \\
\hline Mão-de-obra & $7,1 \mathrm{~h}$ & 0,284 \\
\hline Maquinário & $20 \mathrm{~kg}$ & 0,36 \\
\hline Diesel & 38,81 & 0,442 \\
\hline Gasolina & 35,71 & 0,27 \\
\hline Gás & 3,31 & 0,025 \\
\hline Nitrogênio & $3,7 \mathrm{~kg}$ & 0,059 \\
\hline Fósforo & $37,8 \mathrm{~kg}$ & 0,156 \\
\hline Potássio & $18,4 \mathrm{~kg}$ & 0,048 \\
\hline Calcário & $4800 \mathrm{~kg}$ & 1,349 \\
\hline Semente & $69,3 \mathrm{~kg}$ & 0,554 \\
\hline Herbicida & $1,3 \mathrm{~kg}$ & 0,13 \\
\hline Eletricidade & $10 \mathrm{kWh}$ & 0,029 \\
\hline Transporte & $154 \mathrm{~kg}$ & 0,04 \\
\hline Subtotal & & 3,746 \\
\hline \multicolumn{3}{|l|}{ Energia para produção de $1.000 \mathrm{~kg}$ de biodiesel } \\
\hline Grãos & $5.556 \mathrm{~kg}$ & 7,8 \\
\hline Eletricidade & $270 \mathrm{kWh}$ & 0,697 \\
\hline Vapor & $1,3510^{6} \mathrm{kcal}$ & 1,35 \\
\hline Água & $0,1610^{6} \mathrm{kcal}$ & 0,16 \\
\hline Calor & $0,5910^{6} \mathrm{kcal}$ & 0,592 \\
\hline Perdas & $0,310^{6} \mathrm{kcal}$ & 0,3 \\
\hline Aço & $32 \mathrm{~kg}$ & 0,404 \\
\hline Cimento & $56 \mathrm{~kg}$ & 0,106 \\
\hline Total & & 11,409 \\
\hline
\end{tabular}

Fonte: PIMENTEL \& PATZEK, 2005.

maior potencial produtivo são o dendê e o côco, que ainda têm a vantagem de serem culturas perenes e com colheita contínua durante o ano. Isso diminui os dispêndios energético e financeiro para a produção dessas espécies e evita a sazonalidade do fornecimento de matéria-prima, um bônus imenso em relação aos cultivos anuais. Nos Estados das Regiões Central e Sul do país, as culturas anuais são as mais recomendadas. Das nove culturas, quatro são adaptadas para cultivo no Estado do Rio Grande do Sul: mamona (Ricinus communis L.), soja (Glycine Max (L.) Merril), canola (Brassica napus L.) e girassol (Helianthus annus L.).

A adoção de práticas de manejo adequadas, como escolha de cultivares, época de semeadura e adaptação dos sistemas de rotação de culturas, podem amenizar a desvantagem das culturas anuais. Nas décadas de 80 e 90, a cultura do girassol foi amplamente

Tabela 3 - Características das principais culturas oleaginosas do Brasil.

\begin{tabular}{|c|c|c|c|c|c|}
\hline Espécie & Nome científico & Origem do óleo & Teor de óleo (\%) & Meses de colheita por ano & $\begin{array}{l}\text { Rendimento } \\
\text { (t óleo ha }{ }^{-1} \text { ) }\end{array}$ \\
\hline Dendê & Elaeis guineensis L. & Amêndoa & 22 & 12 & $3-6$ \\
\hline Côco & Cocos nucifera L. & Fruto & $55-60$ & 12 & $1,3-1,9$ \\
\hline Babaçu & Orbignya phalerata Mart. & Amêndoa & 66 & 12 & $0,1-0,3$ \\
\hline Girassol & Helianthus annus L. & Grão & $38-48$ & 3 & $0,5-1,9$ \\
\hline Canola & Brassica napus L. & Grão & $40-48$ & 3 & $0,5-0,9$ \\
\hline Mamona & Ricinus communis L. & Grão & $45-50$ & 3 & $0,5-0,9$ \\
\hline Amendoim & Arachis hypogea L. & Grão & $40-43$ & 3 & $0,6-0,8$ \\
\hline Soja & Glycine Max (L.) Merril & Grão & 18 & 3 & $0,2-0,4$ \\
\hline Algodão & Gossypum hirsutum L. & Grão & 15 & 3 & $0,1-0,2$ \\
\hline
\end{tabular}

Fonte: BRASIL, 2005.

Ciência Rural, v.38, n.3, mai-jun, 2008. 
estudada como alternativa para a produção de óleo comestível e para alimentação animal no Estado do Rio Grande do Sul, tendo havido expansão de área de cultivo. Diversos estudos foram conduzidos (SILVA, 1981; SILVA, 1985; SILVA, 1988; SILVA, et al., 1992; SILVA \& ROCHA, 1994; SILVA \& ALMEIDA, 1994; SILVA et al., 1995; SILVA et al., 1997), sendo obtidos resultados que comprovam a aptidão do Estado para a produção de girassol e a integração da cultura em sistemas de rotação com milho, soja e cereais de inverno. SILVA\& MUNDSTOK (1988) concluíram que o teor de óleo em grãos de cultivares de girassol varia de 38 a 47\%. Em experimento com épocas de semeadura, foi observado que uma mesma cultivar pode variar o teor de óleo de 42 a 36\%, diminuindo com o atraso da época de semeadura de agosto-setembro para dezembro. Dessa forma, a época mais favorável para a semeadura do girassol para um agricultor que deseja produzir biodiesel é nos meses de agosto e setembro. Com ciclo curto, de aproximadamente 100 dias, é uma ótima alternativa para participar no sistema de rotação de culturas, possibilitando a semeadura do milho ou da soja após sua colheita. É também uma boa opção para regiões onde o déficit hídrico é um problema, por ser uma espécie com boa tolerância. No entanto, por falta de solidez na comercialização, a área de cultivo foi diminuindo e a pesquisa desestimulada.

Mais recentemente, a canola surge como uma alternativa de inverno para o Estado, onde atualmente apenas a aveia e o trigo têm expressão comercial. A quebra da sucessão de gramíneas no período do inverno com espécies de outras famílias, como a Brassicaceae, facilita o controle de pragas, doenças e plantas daninhas nos sistemas de produção. De ciclo curto, aproximadamente 100 dias, pode ser semeada no mês de maio, permitindo a semeadura de milho ou soja em sucessão.

Apesar de trazer em vantagens ao sistema agrícola, as produções de canola e de girassol para uso como biodiesel podem ser consideradas incoerentes por utilizarem óleos nobres para alimentação humana, que são ricos em ácidos graxos poliinsaturados e benéficos e valorizados para a alimentação. O óleo de rícino, extraído da mamona, seria a melhor opção para a produção de biocombustível, por não ser adequado ao consumo humano. A rusticidade da espécie, altamente tolerante ao déficit hídrico, torna a planta promissora como produtora de biodiesel, mas o florescimento dessincronizado e a alta deiscência de frutos a tornam uma alternativa de cultivo apenas para pequenas propriedades. Outras desvantagens, como ciclo longo, de aproximadamente um ano, e o látex, que pode provocar ferimentos em quem manuseia a planta, exigem um estudo mais cauteloso desta planta como uma alternativa. A "torta" (resíduo da extração) possui uma substância de altíssima toxicidade, a ricina, e um conjunto de glicoproteínas alergênicas (CARVALHO, 1978; KOUTROUBAS et al., 1999; AUDI et al., 2005), que permitem que o resíduo seja utilizado para alimentação animal somente depois de passar por tratamentos que o torne detoxificado. A alerginicidade é um risco também para as pessoas que trabalham nas indústrias de extração de óleo, expostas à poeira elevada. Além disso, o óleo de mamona é mais viscoso que a maioria dos óleos vegetais, devido principalmente ao ácido ricinoléico, o que pode prejudicar o mecanismo de atomização do jato de combustível e o funcionamento do sistema de injeção (COSTA NETO et al., 2000). Com o intuito de viabilizar a utilização do biodiesel de mamona, propõe-se a mistura com ésteres de outras oleaginosas, de viscosidade inferior. O nãoaproveitamento da mamona para outros fins também pode ser visto como uma desvantagem, considerandose que o produtor fica dependente apenas do mercado do biodiesel. Nesse aspecto, a ampla utilização da soja a torna uma opção segura ao produtor, pois a comercialização dos grãos não fica na dependência do sucesso do biodiesel. Apresenta ainda a vantagem de ser uma fixadora de nitrogênio, o que favorece o balanço energético. Muitos trabalhos têm sido feitos para se produzir combustível de melhor desempenho (KINNEY \& CLEMENTE, 2005). Porém, o baixo teor de óleo nos grãos proporciona uma baixa produtividade de óleo.

Mesmo com algumas desvantagens, o cultivo dessas espécies pode contribuir para o desenvolvimento da agricultura em regiões de menor disponibilidade hídrica do Estado, servindo também como estímulo a pequenas agroindústrias. A diversidade de espécies é importante para se reduzir a capacidade ociosa das indústrias de esmagamento e de extração, que assim passam a receber matéria-prima em vários meses do ano e não apenas após a colheita de uma espécie.

O aumento da área agrícola para produção de bioenergia é um aspecto polêmico, visto que o setor vem sendo acusado de degradar o ambiente e de ser emissor de gases de efeito estufa (PHILIP ROBERTSON et al., 2000). No entanto, vários autores consideram que a agricultura conservacionista, utilizando o sistema de plantio direto na palha, é uma fonte de seqüestro de carbono. Dessa forma, o ônus ou o bônus da produção de biodiesel para o ambiente está na dependência das práticas agrícolas que serão utilizadas nos sistemas de produção das diferentes espécies. Dessa maneira, 
deve-se encarar a produção de biodiesel como uma alternativa para diminuir se o problema atual de consumo de petróleo, junto com outras fontes de energia renovável, como bioetanol, gás natural, carvão, hidroelétricas e o aproveitamento de resíduos de lavouras, como o bagaço de cana e a casca de arroz.

Competição da produção de biodiesel por recursos naturais

A produção de grãos para combustível utiliza recursos naturais em maior quantidade que a produção de óleo diesel de petróleo. Dados do USDA e do USDE (1998) mostram que, para se produzir a quantidade de óleo diesel necessária para gerar a energia para um motor de $1 \mathrm{HP}$ funcionar durante uma hora, é gasto menos de 1 litro de água. Para a produção dessa mesma quantidade de energia a partir do B20, o consumo é de 18 litros de água e, para produzir o B100, são consumidos mais de 85 litros de água. Nutrientes, que não são utilizados na produção de óleo diesel, são usados em larga escala na produção de biodiesel, deixando de serem utilizados para produzir alimentos. STEWART et al. (2002) analisavam as reservas de fosfato de rocha em vários países e estimaram o tempo de duração dessas reservas, sendo vendidas em diferentes preços, considerando a demanda atual. No cenário mais otimista, com a tonelada do adubo sendo vendida a US\$ 90,00, o mundo possuiria uma reserva suficiente para 343 anos, mas o Brasil para apenas 84 anos. Se a tonelada do adubo for vendida a US\$36,00, as reservas mundiais seriam suficientes para apenas 88 anos e as reservas brasileiras para 75 anos.

À exemplo da competição que existe entre o álcool combustível e o açúcar, os preços do biodiesel e dos alimentos derivados de grãos oleaginosos podem passar a competir no mercado. Segundo o DIEESE, o preço do álcool no Brasil passou de menos de $\mathrm{R} \$ 1,00$ em março de 2005 para mais de $\mathrm{R} \$ 1,60$ em março de 2006. Esse aumento é justificado pela valorização do açúcar no mercado internacional que, no mesmo período, passou de menos de US\$ $0,22 \mathrm{~kg}^{-1}$ para US\$0,47 $\mathrm{kg}^{-1}$.

\section{CONSIDERAÇÕESFINAIS}

O biodiesel apresenta vantagens ambientais em relação ao óleo diesel; porém, o balanço energético varia conforme o sistema utilizado no cultivo das espécies produtoras de óleo. O cultivo dessas espécies exigirá adaptação do sistema agrícola, favorecendo a rotação de culturas, e aumentará a área agrícola, além de intensificar o uso de áreas já utilizadas. Assim, o ônus ou o bônus que a produção do biodiesel trará ao ambiente depende do sistema agrícola utilizado. Cabe então a ressalva de que o biodiesel é uma alternativa para a diminuição do uso de petróleo, não um substituto.

A produção de combustível compete com alimentos por recursos naturais durante a sua produção e por preços durante a comercialização.

\section{REFERÊNCIAS}

AUDI, J. et al. Ricin poisoning-a comprehensive review. Journal of the American Medical Association, v.294, n.18, p.2342-2351, 2005.

BARNWAL, B.K.; SHARMA, M.P. Prospects of biodiesel production from vegetable oils in India. Renewable \& Sustainable Energy Reviews, v.9, n.4, p.368-378, 2005.

BRASIL. MINISTÉRIO DA CIÊNCIA E TECNOLOGIA. Plano Nacional de Agroenergia. Brasília, 2005. 120p.

CARVALHO, M.E.A. Estudos para a obtenção de concentrados de proteínas da mamona desintoxicados e desalergenizados. 1978. 78f. Dissertação (Mestrado em Bioquímica) - Programa de Pós-graduação em Bioquímica, Universidade Federal do Rio de Janeiro.

COSTA NETO et al. Produção de biocombustível alternativo ao óleo diesel através da transesterificação de óleo de soja usado em frituras. Química Nova, v.23, n.4, p.531-537, 2000.

FREDERIKSSON, H. et al. Use on-farm produced biofuels on organic farms- Evaluation of energy balances and environmental loads for three possible fuels. Agricultural Systems, v.89, n.1, p.184-203, 2006.

GREENE, D.L. et al. Have we run out of oil yet? Oil peaking analysis from an optimist's perspective. Energy Plicy, v.34, n.5, p.515-531, 2006.

INTERNATIONAL ENERGY AGENCY. World oil supply and demand. 2005. Acessado em 01/09/2006. Online. Disponível: http://omrpublic.iea.org/omrarchive/11mar05tab. pdf \#s e a r ch = \% $22 \% 22$ world $\% 20$ o il $\% 20$ supply \% 20and\%20demand\%22\%22.

KINNEY, A.J.; CLEMENTE, T.E. Modifying soybean oil for enhanced performance in biodiesel blends. Fuel Processing Technology, v.86, n.10, p.1137-1147, 2005.

KOUTROUBAS, S.D. et al. Adaptation and yielding ability of castor plant (Ricinus communis L.) genotypes in a Mediterranean climate. European Journal of Agronomy, v.11, n.3-4, p.227-237, 1999.

JANULIS, P. Reduction of energy consumption in biodiesel fuel life cycle. Renewable Energy, v.29, n.6, p.861-871, 2004.

LAPINSKIENÉ, A. et al. Eco-toxicological studies of diesel and biodiesel fuels in aerated soil. Environmental Pollution, v.142, n.3, p.432-437, 2006.

MA, F.; HANNA, M.A. Biodiesel production: a review. Bioresource Technology, v.70, n.1, p.1-15, 1999. 
MIAO, X.; WU, Q. Biodiesel production from heterotrophic microalgal oil. Bioresource Technology, v.97, n.6, p.841849, 2006.

PHILIP ROBERTSON, G. et al. Greenhouse gases in intensive agriculture: contributions of individual gases to the radiative forcing of the atmosphere. Science, v.289, p.1922-1925, 2000.

PIMENTEL, D.; PATZEK, T.W. Ethanol production using corn, switchgrass and wood; biodiesel production using soybean and sunflower. Natural Resources Research, v.14, n.1, p.6576, 2005

POWLSON, D.S. et al. Biofuels and other approaches for decreasing fossil fuel emissions from agriculture. Annals of Applied Biology, v.146, n.2, p.193-201, 2005.

SILVA, P.R.F. da. Introdução e avaliação de cultivares de girassol (Helianthus annus L.) na Depressão Central. In: REUNIÃO TÉCNICA DO GIRASSOL, 1981, Porto Alegre, RS. Palestras e trabalhos técnicos... Porto Alegre: UFRGS, 1981. p.1-2.

SILVA, P.R.F. da. Sucessão e rotação de culturas. In: UFRGS, Faculdade de Agronomia. Girassol: indicações para o cultivo no Rio Grande do Sul. Porto Alegre: Departamento de Fitotecnia, UFRGS, 1985. p.45-46.

SILVA, P.R.F. da. Establishment of intercropped sunflower and cassava systems at different planting dates and sequence order. In: INTERNATIONAL SUNFLOWER CONFERENCE, 12. 1988, Novi Sad. Proceedings... Novi Sad: International Sunflowers Association, 1988. p.378.

SILVA, P.R.F. da; MUNDSTOCK, C.M. Época de semeadura. In: _. Girassol: indicações para o cultivo no Rio Grande do Sul. 2.ed. Porto Alegre: UFGRS: 1988. p.13-17.
SILVA, P.R.F. da et al. Avaliação do sistema de consórcio de substituição de girassol e soja com e sem dessecação química. Turrialba, v.42, n.2, p.113-116, 1992.

SILVA, P.R.F. da; ROCHA, A.B. Exigências térmicas e características agronômicas de cultivares comerciais experimentais de girassol na depressão central do Rio Grande do Sul. Ciência Rural, v.24, n.1, p.55-58, 1994.

SILVA, P.R.F. da; ALMEIDA, M.L. de. Resposta de girassol a densidade em duas épocas de semeadura e dois níveis de adubação. II Características de planta associadas a colheita. Pesquisa Agropecuária Brasileira, v.29, n.9, p.1365-1271, 1994.

SILVA, P.R.F. da et al. Densidade e arranjo de plantas em girassol. Pesquisa Agropecuária Brasileira, v.30, n.6, p.797-810, 1995.

SILVA, P.R.F. da et al. Manejo do solo e adubação na cultura do girassol em sucessão a aveia preta. Pesquisa Agropecuária Brasileira, v.32, n.6, p.641-647, 1997.

STEWART, W.M et. al. Phosphorus as a natural resource. In: SIMS, J.T.; SHARPLEY, A.N. Phosphorus: agriculture and environment, n.46, p.3-22, 2002.

UNITED STATES DEPARTMENT OF AGRICULTURE; UNITED STATES DEPARTMENT OF ENERGY. An overview of biodiesel and petroleum diesel life cycles. 1998. 47p.

ZHANG, Y. et al. Biodiesel production from waste cooking oil: 1. Process design and technological assessment. Bioresource Technology, v.89, n.1, p.1-16, 2003. 